lowing along the practice of the London surgeons its use may be preceded by the more pleasant nitrous oxid gas.

In the use of ether in removing adenoid growth from the vault of the pharynx, the anesthetic should be used to complete relaxation.

The writer is not in sympathy with those who use it short of this stage and has many times witnessed operations which have been delayed and complicated by the struggles and cries of the patient.

Once complete relaxation and insensibility have been obtained the anesthetic may be permanently withdrawn and the operation proceeded with, uninterrupted by any movement on the part of the patient. Given in this manner it is quickly recovered from and is much less liable to produce vomiting and other unpleasant effects.

The same method of procedure is applicable in those cases in which it is found necessary to remove both the faucial and pharyngeal tonsils. Here, however, it is best to push the ether a little more thoroughly than is the case where the simple adenoid operation is done, for the reason that after excision of the tonsils some little time is consumed in allowing blood to escape from the mouth before curetting the vault.

Incidentally the position of the patient during these operations is of importance. The most satisfactory results are obtained in operations in the naso-pharynx in that position which places the posterior wall of the pharynx and naso-pharynx in the most dependent position. This is accomplished by the Trendelenburg position or a modification of the same. By this method we are not delayed by gurgling of blood in the pharynx and symptoms of asphyxia and the danger to respiration is at a minimum.

At the house of our patient the true Trendelenburg position is not always feasible. In this case all that is necessary to obtain the same result is to allow the head to hang over the edge of table or bed. The blood is sponged from the pharynx by an assistant, the patient is turned on the side and the blood permitted to escape from the nose or the angle of the mouth.

Pharyngeal operations.-Nearly all the operative measures the laryngologist is called upon to perform in the pharynx can be accomplished under local anesthesia.

Eucain is to be recommended in this locality. It causes less discomfort to the patient and it is also probably less likely to give rise to unpleasant general symptoms.

Hypertrophied tonsils, the most frequent condition calling for surgical interference in the pharynx, when uncomplicated by anenoids at the vault, may readily be excised without the use of a general anesthetic.

This operation is accomplished so quickly, with so little pain (which latter may be annulled by local anesthesia) and the work can be done so effectively that it seems an unnecessary complication to induce general anesthesia.

In nervous, irritable children in whom the shock of operation and the necessary restraint might prove serious to the nervous system of the child, transient anesthesia is to be recommended. Nitrous oxid is eminently useful in cases of this nature.

Hypertrophied tonsils, associated with adenoid vegetations at the vault should be treated in a similar manner to that spoken of in the discussion on the removal of hypertrophied pharyngeal tonsils.
Laryngeal operations.-All intra-laryngeal operations are performed under local anesthesia.

Cocain is preferable in the larynx, because its anesthetic properties are equal to eucain and it is distinctly less irritating and consequently less liable to produce unpleasant spasms. By local anesthesia the modern laryngologist is enabled to remove growths formerly deemed inoperable or only removed by splitting the thyroid cartilage, thus causing subsequent impairment of the voice.

The various major operations, such as laryngectomy, thyrotomy and tracheotomy, are accomplished under general anesthesia. Recently, however, a number of tracheotomies have been done with cocain injected along the line of operation as the only anesthetic employed.

This method may occasionally be possible in adults or in children already narcotized by prolonged dyspnea, but it would be exceedingly unwise to advocate it as of general utility in children, upon whom we are most frequently called upon to do this operation.

1804 Chestnut Street.

\section{TONSIL AND ADENOID OPERATIONS UNDER ANESTHESIA BY NITROUS OXID, AND NITROUS OXID AND OXYGEN: A PRELIMINARY REPORT.}

Presented to the Section on Laryngology and Otology, at the Forty-eighth Annual Meeting of the American Medical Association. held at Philadelphia, Pa., June 1-4, 1897.

BY W. E. CASSElbERRY, M.D., AND F. MENGE, M.D. CHICAGO. ILL.

The desirability of an anesthetic that would obviate the general objections pertaining to chloroform and ether in operation on tonsils and adenoids has been the source of much research. The chief objection to chloroform lies in its danger; bromid of ethyl has scarcely attained any greater confidence; ether, while reasonably safe, is so prolonged in its effects as to be incon. venient for this purpose. Nitrous oxid alone has been employed by a few operators, notably at the Central London Thruat Hospital, but the available operating period from a single administration is almost too brief for the satisfactory removal of both the tonsils and adenoids. Experience has proven this anesthetic, however, to be safer than any other and to possess the advantage of a rapid revival of the patient; therefore following Gardner, Hunt and Hewitt of England, and Van Arsdale of New York, we have sought to modify the action of nitrous oxid by the addition of oxygen in order to render it more available and less objectionable for this operation.

As regards the safety of nitrous oxid, it is estimated by $\mathrm{H}$. C. Wood that it is given in 750,000 cases annually and we have been able to learn of but thirteen deaths fairly attributable to it.

The anesthetic effects of nitrous oxid gas were first noted by Sir Humphrey Davy, about the end of the last century, and it has since, from year to year, come into more general use.

Under nitrous oxid the respiration becomes slower and if the gas be pushed, a complete cessation of respiratory movements eventually takes place. The heart beats quietly, fully and regularly under this gas. The pulsations are somewhat slow in profound narcosis. There is, however, but slight danger from heart failure resulting from the inhalation. 
In animals killed by nitrous oxid gas the heart goes on beating even after the respirations have quite stopped. It is therefore less important to watch the pulse than the respiration.

So it will be seen that in the administration of nitrous oxid, the respiratory tract is most involved, the respiration usually rapid from the excited condition of the patient, after a short though variable period of inhalation of from one to two minutes, becomes deep and even snoring, and a complete anesthesia with unconsciousness is produced, lasting from thirty secconds to one and one-half minutes. But accompanying this and keeping pace with it, we have all the phenomena of asphyxia, due to a deficiency of oxygen in the air passages and tissues of the body.

One of the most evident means of avoiding this formidable objection with its cyanosis, stertor and general asphyxiation, was the addition of pure oxygen gas to the nitrous oxid, but, however, in such proportion that its value as an anesthetic should not be impaired.

The question as to whether nitrous oxid is an anesthetio per se or depends upon the accompanying asphyxia for its anesthetic effect, has never been definitely determined. From the fact that anesthesia can be produced by the gas with from 5 to 12 per cent. of oxygen it would seem that nitrous oxid is, in itself, an anesthetizing agent, although even then the slight asphyxia usually induced doubtless serves to augment the anesthetic effect.

A number of combinations have been used by dif. ferent authors with varying success. The late Prof. Paul Bert, by administering under increased atmospheric pressure a mixture of oxygen and nitrous oxid, succeeded in producing a prolonged and profound anesthesia, at the same time maintaining normal oxygenation of the blood. He used 20 per cent. of oxygen, for the reason that the same percentage exists in atmospheric air. He obtained the necessary atmospheric pressure by having built, a large glass operating chamber, in which he together with his assistants and the patient were hermetically sealed, the desired density then being regulated through the medium of an air pump.

Van Arsdale sought to dispense with this chamber by substituting a tight fitting mask, giving the gas with 10 per cent. of oxygen, under pressure, with good results.

Hewitt of London, after experimenting upon a number of cases, found a 12 per cent. oxygen mixture produced anesthesia after an average inhalation of 126 seconds, of 44 seconds duration, while the average quantity of gas used was $8 \frac{3}{4}$ gallons.

Having seen a number of anesthesias for dental purposes, we used at first the pure nitrous oxid on several cases and found that the gas, when pushed to its physiologic effects, afforded an anesthesia sufficient for operating purposes of about forty-five seconds duration, so we at first abscised the tonsils, then re-applied the gas and finished the adenoids, practically, with a second anesthesia.

Then we tried a 25 per cent. oxygen mixture but after twelve minutes and no anesthetic effect, we substituted the pure nitrous oxid, the patient being fully under the influence, to loss of eye reflexes, in less than a minute.

After this, some six cases were operated on with an approximate 10 per cent. mixture and with two applications of the gas, the average time of the first admin- istration being about four minutes, while that of the second was about two.

Then we still further reduced the amount of oxygen and anesthetized completely with an approximate 5 per cent. mixture without much cyanosis or asphyxia in all average of two minutes. We also found that this mixture so lengthened the available anesthetic operating time, that we could remove both tonsils and the adenoids with one application of the gas, this complete operation occupying about one minute.

This is essentially a time-saving operation, and to do it every detail must be arranged beforehand; every instrument that could possibly be of use must be within easy reach of the operator. We inserted the mouth gag, using an O'Dwyer gag, before beginning the anesthetic. The patient was then placed in our usual operating position on the lap of an assistant, the head being on the assistant's left shoulder. The operator then turned on the gas from both cylinders, filling the intermediate rubber reservoir, whence the mixture was conveyed to the patient through a rubber tube to a snug-fitting mask, allowing absolutely no air to enter, this mask being held tightly over the nose and wide open mouth of the patient by the operator until the full effect of the anesthetic had been reached, recognized as with other anesthetics, by unconsciousness, loss of eye reflexes, etc.

The mask being removed, the patient is ready for operation. Both tonsils were at first abscised, in half the cases by a Mathieu and the other half with a Casselberry tonsillotome, and the adenoids were then immediately removed by a Gottstein curette. This operation can be performed without undue haste in one minute in the average uncomplicated case, but we do not wish to be understood as advocating such a quick method in every case, for when the tonsils are bound down by adhesions or other complications exist which require time and deliberation during the operating, then nitrous oxid is not a suitable anesthetic.

We have operated on fifteen cases in this manner; all were children, the youngest being $2 \frac{1}{2}$, the eldest 11 years of age, five were boys and ten were girls, and all but one case were afflicted with both enlarged tonsils and adenoids. The patients were in all degrees of excitement, but immediately after the first two or three spasmodic inhalations they became calm and the respirations were full and regular.

The appended schedule gives the time of the first inhalation, time of operation on tonsils, the second anesthesia, the "adenoids" and age.

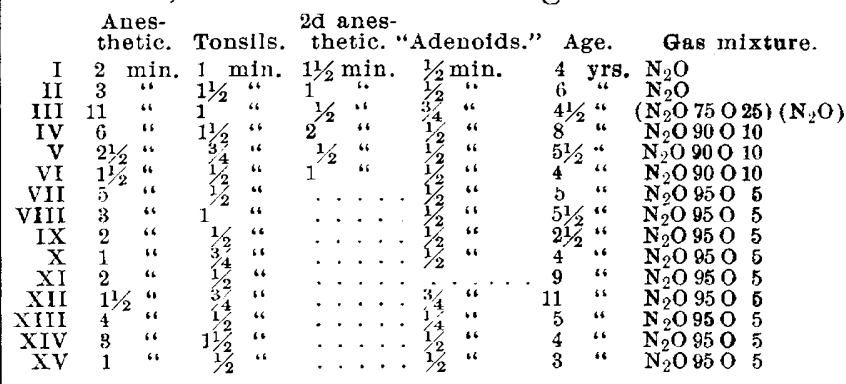

The apparatus required is rather cumbersome and heavy and consists of the face piece or mask, the rubber reservoir and the cylinders of oxygen and nitrous oxid. The mask is made of a metal frame which is covered by rubber, which at its edge, at the point of contact with the face, is in two layers and may be inflated. It is fitted with an expiratory valve as well as one whereby the gas may be turned on or off. 
The rubber bag or balloon has a capacity of five gallons and serves as an approximate measure of the amount of gas consumed as well as for the mixing of the gases and on it, also, we made the necessary pressure to force the gas to the patient. This apparatus we purpose modifying by the substitution of a cylindric gasometer for the rubber bag.

Nitrous oxid gas is now put into the liquid from under high pressure and keeps in this condition indefinitely, being placed in steel bottles. Oxygen in copper cylinders is now well known, while rubber tubing, with a junction, forms the connection with the bag.

The advantages of this mixture of gases over chloroform and ether are: 1, the absence of danger; 2 , no preparation whatever is necessary; 3 , the upright position usually desired may be safely assumed; 4 , hemorrhage seems in no way to be affected by it; 5 , the time of the whole proceeding is greatly lessened, from an hour and a half to as many minutes; 6 , the after-effects, the vomiting and retching, are entirely obviated, and the patients may be safely removed to their homes within fifteen minutes.

It would only be fair to state the disadvantages that have occurred to us: 1 , somewhat cumbersome apparatus required; 2 , greater number of assistants desirable; 3, haste with which it is necessary to operate.

In reference to the haste, after some experience with the method, the operator finds that he has more time at his disposal than he at first thought possible.

We would say in conclusion, that we have in nitrous oxid mixed with a small percentage of oxygen, an anesthetic that is relatively devoid of danger, taking only a few minutes to administer, and giving a sufficiently long narcosis for the ordinary tonsil and adenoid operation and which is particularly suitable for dispensary use.

British Medieal Journal, Feb. 21, 1891

American Journal of the Medical Sciences, August, 1891.

New York Medfcal Journal, March 7,1881

Dental Cosmos, November, 1891.

Lancet, 1889 .

Buxton: Anestbetics.

B.C. Wood: Therapeutics.

Deutsche Medicinische Wochenschrift, 1886.

Comptes Rendus des Séances de la Société de Biologie.

Lonảon Clinical Journal. Aug. 26, Sept. 2, 1896.

DIsCUSSION ON PAPERS OF DRS. GIBBS ANJ MENGE.

Dr. RoE-Some years ago, before cocain was introduced, I used nitrous oxid gas for small operations and particularly cautery operations in the nose, but since cocain was introduced I have abandoned its use altogether. Nitrous oxid gas and bromid of ethyl are serviceable only in operations requiring but a few moments for their performance; whereas in operations that are at all prolonged they are entirely insufficient, and cocain, chloroform, eiher or some other less evanescent anes. thetic, either local or general, must be resorted to. In some cases the operation for the removal of adenoid growths and also enlarged tonsils can properly be performed in from fortyfive to sixty seconds, but in many other instances the conditions are such that it is absolutely impossible to properly perform the operation thus quickly ; therefore nitrous oxid gas or bromid of ethyl are adapted only to a limited class of cases. In adults and older children I have found cocain anesthesia quite sufficient for these operations, but in young children I use chloroform only. For hospital and clinical work, nitrous oxid gas and bromid of ethyl simply have the advantage of expediting matters somewhat. I have not only had no trouble from the use of chloroform, but have had most excellent results and have not felt the necessity of using bromid of ethyl, which is sometimes troublesome to procure perfectly pure, or of bothering with the cumbersome apparatus which the use of nitrous oxid gas requires. In children the use of chloroform is very simple and perfectly safe. It affords ample time for the performance of the operation, and with the proper manipulation of the child there is no danger of the inspiration of blood into the trachea, nor are there any other conditions that contraindicate its use.
In adults, the chief danger in the use of chloroform lies in the concentration of the vapor or in the exclusion of sufficient oxygen, and it is to obviate this danger that oxygen gas mixed with chloroform vapor is employed. Three years ago, while in London, I procured a new apparatus for administering chloroform, devised by Krohne \& Sesemann, and since that time a similar apparatus has been made by George Tiemann \& Co. of New York. The mask in this apparatus is so arranged that there is free ingress through the center for atmospheric air, while the chloroform is propelled into it, in the form of vapor, by passing the air through the bottle containing the chloroform. When there is prospective danger from the use of chloroform, oxygen gas can be substituted for the ordinary atmospheric air forced through the chloroform liquid in the bottle. By the employment of this apparatus, the use of chloroform is not only rendered perfectly safe for children, but also for all adulte in whom there is not some physical complication to contraindicate its use.

In Paris they use chloroform entirely as a general anesthetic and it is not considered dangerous. I have in a number of instances seen the Parisian surgeons push the chloroform far beyond the point that we would consider safe and the patients recover all right.

We may reasonably conclude that the use of nitrous oxid gas and bromid of ethyl as anesthetics is of special service in those adenoid, tonsillary and nasal operations in children and nervous and sensitive adults which can be quickly performed, and especially in clinical and hospital work, in which it is necessary or desirable to dispose of the cases quickly; but that in many of these same operations, which can not be so expedited and at the same time properly performed, other anesthetics, as ether or chloroform, must be resorted to.

Dr. Martindale-My knowledge of the use of nitrous oxid has been limited to the observation of 100 cases in the Central Hospital of London. My personal use of nitrous oxid is limited to the external auditory canal and peritonsillar abscess. My adenoid operation requires more time. Dr. Mackenzie has published his impressions as to the use of cocain in the nasal passages in connection with general narcosis. Since then it has been alluded to by Dr. Cohen and others. I have found it a valuable adjunct, and several of my colleagues in Minneapolis have found it useful. I would not undertake an extensive operation on the naso-pharyn $x$ without first spraying it with a solution of cocain. The use of the general anesthetic is attended with less danger.

Dr. RoE - Cocain does not seem sufficient to take away the pain. Bromid of ethyl makes the patient half unconscious, so that he is conscious of the operation but feels no pain.

Dr. SCHFPPEGRELL-I would use bromid of ethyl where an operation can be done in a short time, as there is comparatively less danger in a shorter anesthesia. If $\mathrm{I}$ can not complete the operation with the short anesthetic, I give chloroform. Some nine months ago I substituted eucain for cocain. I have used bromid of ethyl for four or five years in all cases of short anesthesia, without bad effects. Everything should be ready beforehand in these operations. Where children are old enough to have the gag placed in the mouth without exciting them, it hould be done beforehand. If this is not possible, give the anesthetic to a slight extent, then apply the gag and complete the operation. I oppose prolonging the anesthesia to operate on both tonsils and adenoids. I have operated in this way on a patient over 18 years old and have seen severe hemorrhage. In case we have this complication we should limit ourselves to either the adenoids or the tonsils. In using bromid of ethyl it is important to get pure preparations. In one case a druggist sent me nitrite of amyl. I have nothing to say against nitrous oxid except that it requires such complicated apparatus. Unless some good reason can be found against bromid of ethyl, I prefer to use it if the pure article can be obtained. I know of no fatal results.

I think the difficulties of operating in the sitting position have been rather exaggerated. I always operate in that position, with an assistant holding the head of the patient well forward. The advantages over the Trendelenburg position are marked, because the patient sits in front of you, and the relation of the parts is better maintained.

It would be impossible for me to do adenoid operations in forty-five to sixty seconds. I think many of us would require a longer time than was mentioned in the paper.

Dr. Burss - I say emphatically that adenoid operations on children ought to be done under general anesthesia. In Europe and in many parts of this country it is done without anesthesia, but I consider this almost cruelty. If you do not complete the removal at one operation, you will not induce the child to submit a second time. We may remove adenoid vegetations in a child under 1/2 years old without anesthesia, because the 
nervous system is not so highly developed, and the child will not remember so well. For general anesthesia in children I prefer chloroform. It is just as safe as ether and more agree. able. Since bromid of ethyl and nitrous oxid have been used, I have tried them in a number of cases. One objection is that we never know exactly when the right moment has come to operate. In some cases when the arm drops there is sufficient anesthesia, but in others there is not. Also you have to introduce the gag before operation. With a timid child the preparations beforehand will make him dread the operation. The reflexes are not abolished and the child may scream. An operation under general anesthesia should be done either in a hospital or at the house of the patient, and not in the office.

As to the nitrous oxid, I operated some years ago on a dental student who had hypertrophy of the turbinal. I did it in the anesthetizing room at the dental college. I was surprised to see how easily it could be done, and I was also alarmed at the almost careleseness with which the dental surgeons produced a case of cyanosis. In the fifteen or sixteen cases in which I have used nitrous oxid, it was given by a dentist. The patient has the disadvantage of seeing the preparations beforehand, and unless he has fortitude he gets frightened. General anesthesia should always be used in adenoid operations, and the method is largely a matter of choice. I think that chloroform with the addition of 5 per cent. of oxygen will be of value.

Dr. MYLES-The shock of giving a child ether I think is as great as that of doing an operation. In regard to the operation, we may make an actual diagram and topographical description of the disease, then line out as much as nature intended us to have of the tonsils. If you operate on children who have fairly gond tonsile, you will have very little trouble. If you pass your finger up into the posterior nares and tonsils and the child has adenoid growths, you will also find large hypertrophy of the lingual tonsil and fauces. But to run a curette up there and remove all this tissue takes ten or fifteen minutes. One firm sweep upward and backward will remove a larger amount than you can get by any other process. The instrument must be suited to the case, and must be of proper size and properly sharpened, so that it will engage the tissue and not bounce over it. I do not think it right to subject the child to an anesthetic, especially to ether when the work can be done without it. We should use the simpler methods.

Dr. STUCKY - I am opposed to general anesthesia in operations for adenoids except in very rare cases. There is more shock in giving the child an anesthetic than there is in the operation. Make an application of cocain and then place a sheet around the child, fastening it behind and before, and slip in the mouth gag. After that there will be no more resistance or screaming and you can perform the operation thoroughly and with less shock. Keep the patient quiet for several hours after operation.

Dr. Merrick-I think there is more danger of hemorrhage with general anesthesia. I operated on a child four years old, and curetted under cocain. There was bleeding from 12 that day until 12 at night. If I had used a general anesthetic I think the child would have died. I have operated in about 100 cases and have used nitrous oxid gas in two and chloroform in one. A very severe hemorrhage followed the use of the anesthetic. I investigated the proceedinge of laryngologic bodies for one year. I found five cases of death from tonsillotomy. I did not find a single case where fatal hemorrhage occurred except where a general anesthetic was used. Meyer used no general anesthetic. In my clinic I never think of using one. I have a grooved table upon which the patient is held by an assistant and the operation is completed in one minute. The child may cry. Two minutes after the child is released it is all right. Only in very extensive cases is a general anesthetic justifiable. You can do these operations, certainly in 95 per cent. of cases, without any risk except that of hemorrhage.

Dr. Buiss-I have just left a little patient, five years old, whose throat I have curetted without any anesthetic whatever. He was just as fond of me as though I had not done it. A great deal that is said on this subject is overdrawn.

Much of this adenoid tissue is absolutely physiologic, and the line of demarcation must be drawn with great caution. In the younger cases we can hardly use the visual exploration with any satisfaction. Digital exploration is almost a necessity. In the matter of curettement, the finger is far better than any other instrument. We have the pulp of the finger as a protection and can squeeze out the adenoid tissue with a minimum of bleeding and danger. If a large mass is to be removed, we can do it in nine cases out of ten without an anesthetic. Where we have a large operation to do we must have a general anesthetic, and in Philadelphia this will usually be ether.

Dr. MACKENZIE-Unless indications are strongly to the con- trary, and unless the child is rebellious, I prefer to operate on adenoid growths without an anesthetic. It takes longer, but I make a more complete operation. It is sometimes necessary to prevent recurrence, to employ vigorous curettement. If so I sometimes resort to an anesthetic, generally to bromid of ethyl. If a general anesthetic is to be administered to children, I prefer to give chloroform first until comparative quiet is secured, and then keep up the narcosis with ether. I have used bromid of ethyl in these cases for years, and have never had an accident. The drug must be pure, however. It can now be obtained in hermetically sealed tubes. Care must be taken also to exclude the air. If these precautions be taken I think it is perfectly safe. As to the removal of adenoid growths and both tonsils in forty-five to sixty seconds, in my hands the operation would not be complete. It seems to me absolutely impossible in a very short time to reach every nook and cranny of the naso-pharynx and to be sure that the extirpation is complete.

Dr. MaRTindale-As to using ether in the upright position, I have seen one death from a dentist using ether in his dental chair, and that is enough to deter me from using it in that way. I have used nitrous oxid with very pleasant results. After one becomes accustomed to the alarming appearance of the patient I think there is no danger; and if Dr. Casselberry has added oxygen, which increases the narcosis and lessens the danger, this will be an ideal anesthetic. But the majority of cases which need an anesthetic should be placed under narosis for a longer time than one minute.

Dr. CoBB - I will say a word in the defense of ether in the upright position. In the Massachusetts General Hospital, ether has been used. In the last eight years we averaged over four adenoid operations a week, and there has not been one death. I think that is fairly good evidence of the safety of ether.

Dr. Gibbons-I would call attention to the necessity for knowledge as to forced respiration, etc. A patient who does not recover from ether or chloroform does not die for some time. We should do something to restore animation, besides the ordinary traction of the tongue. A surgeon is criminally responsible if he has not a regular apparatus for this purpose, or at least a common pair of bellows. If he has a compressed air tank he can resort to that. He should certainly have oxygen. Forced respiration should be kept up for at least six hours. Life will sometimes come back after six hours when it will not after four or five. If you have nothing better, insert the compressed air tube and push it down into the trachea. You may find it convenient to do tracheotomy. At least 90 per cent. of adenoid growths can be removed without a general anesthetic. When a general anesthetic is needed I use chloro. form and nitrous oxid.

Dr. GibB - In Philadelphia we largely use ether, Our expe. rience with browid of ethyl has been such as to deter us from its use ; but I think the bad results were largely due to the impurity of the drug. The same objection may be offered to nitrous oxid and bromid of ethyl, the short period of anesthesia. This is especially true if the combined operation for adenoids and hypertrophied tonsils is undertaken. There are many adenoids that it is not necessary to remove at all, and still thers can be removed by so simple an operation that wo anesthetic is needed. But in cases of large adenoid, I still believe that ether is the most desirable form of anesthetic. Nitrous oxid and bromid of ethyl give too short a time.

The Chatrman-The only way of harmonizing the diversity of views is the natural one of making a proper selection of cases. No fixed line of treatment could be laid down for all cases even to the anesthetic preferred. There are adenoids which can not be removed in one, two or three minutes, and there are those which can, or at least which can be sufficiently removed for practical purposes. There are some cases where it is desirable to make the operation on the faucial tonsile and adenoids at different times, but usually it is best to do a combined operation. Complications may arise, but you would find no general surgeon willing to make two bites of a cherry on so small a surgical measure, especially if the operation be done under a general anesthetic. You can treat hemorrhage just as well in the case of a child under anesthesia as without.

Dr. Menge has taken an extreme position in saying that nitrous oxid with oxygen is absolutely free from danger, for that is true of no anesthetic ;it is relatively free from danger. There is also slight asphyxia, even with the oxygen. It is only intended for institution and office use, where the apparatus can be kept in readiness. As to operating without anesthesia, in some children it can be done very well and in others it can not. As to the citation relative to dangerous hemorrhage with an anesthetic, I have elsewhere reported a fatal case from the practice of a friend following tonsillotomy without an anes- 
thetic. The child swallowed the blood and the hemorrhage was not observed until too late. If there is hemorrhage you can stop it better with an anesthetic than without. With nitrous oxid the anesthesia is so brief that the patient would have to be re-anesthetized by other means in the emergency of a dangerous hemorrhage.

\section{SOCIETY PROCEEDINGS.}

\section{The Quarantine Convention of the South Atlan- tic and Gulf States.}

(Concluded from page 490.)

Ferbuary 11-Morning Session.

The convention was called to order at 10 o'clock and the Chair announced that the order of business would be the discussion of the papers on "National Quarantine" and "A National Bureau of Health" (vide Journat, February 26, p. 490 ).

It was ordered that the discussion of the report of the Committee on Resolutions, when made, be coupled with the discussion of the papers.

The report of the special committee on the resolution introduced by Dr. John B. Hamilton, relative to dangerous infected ports, to provide for the maintenance of a medical force at those ports and the calling of an international quarantine conference, was read. The report favored the adoption of the resolution and the drafting of a memorial to Congrese to give it effect, and was unanimously adopted.

$$
\text { NATIONAL QUaRANTINE. }
$$

The following is an abstract of the paper read on Thursday by Dr. H. B. HoRLBECK, health officer of Charleston, S. C., and ex -president of the American Public Health Association.

The subject of National quarantine is a function affecting the vital interests of the entire Nation, and it is a task which has its peculiar character, viz., the protection of the different States and municipalities, with the privilege of self-government in those States and municipalities unimperiled.

It would appear that this condition is the pivotal point in the adjudication of National quarantine: To have furnished the fullest and amplest assistance and co-operation by the Nation and to permit intelligent and willing work by the State and municipality. The privilege of our self-control in these matters is the very foundation stone of our civilization, and the abrogation of the power of a municipality to be the final arbiter in her government of her health interest would be the destruction of a right which carries with it the most sacred duties pertaining to a congregation of human beings established under the constitution of the United States. Salus populi suprema est lex -The health of the people is supreme law, and should be the most absolute right of every municipality.

We therefore, in adding our modicum to "National quaran tine," must above all interests have this sacred right and privilege carefully considered, and we say advisedly "considered." It is not our desire to have these privileges so absolute that an improper or inefficient fulfilment of such duties should not be a matter for adjudication. The rights and privileges of the municipalities being established, we are prepared for discus sion of the relation of National influences in these matters.

The governing body who may have the control and guidance of National quarantine should ever be on the alert to have such general laws of quarantine as may be passed and of force carried into effect. We say general laws, and it is idle in addressing so intelligent and well informed a body to designate such laws which affect the general health of all collected bodies of human beings. Such laws should ever be of force, and as we understand the situation such federal laws are now and have been of force since the act of Feb. 15, 1893, and they are now dominant. All communities who are recreant to their sacred rights and privileges, should at once be brought to a realization of their shortcomings by the controllers of the National laws.

As I am a life-long resident in a sea-coast city, it is but natural that I should more particularly address you in reference to the requirements of the quarantine of such a city in its relation to National proceedings. As Charleston is affected by National quarantine, so are affected the cities of the South Atlantic and Gulf coaste of the United States. The diseases incident to one are incident to all, and the proceedings for the protection of health and for the non-injury to commerce are the same.

There is something new in the situation that is the threat- ened additional powers that are embodied in Senator Caffery's bill, known as Senate Bill No. 2680, additional powers to be given to the Federal Government, practically under the control of the Marine-Hospital Service.

This concise and forcible bill of less than two hundred lines sweeps away all privilege of State or municipality of making any laws as to quarantine, and vests this duty in the nominal hands of the Secretary of the Treasury, as it is a matter of fact that this department of the treasury is under the Supervising Surgeon General of the Marine-Hospital Service. They are simple words, these commencing lines of Senate Bill 2680 but they are ruthless as to any further privilege of the governmental bodies thinking what may be best for the interests of a State containing a seaport city.

The act of Feb. 15, 1893, entitled, "An act granting additional quarantine powers and imposing additional duties upon the Marine-Hospital Service," is destroyed. In the very initial sentence this bill, No. 2680, condemns all privileges of cities judging for themselves or enacting laws for their procedure, and says of the act of Feb. 15, 1893, that it shall be amended by striking out the following words in Section 1 : "And with such rules and regulations of State and municipal health authorities as may be made in pursuance of or consistent with this act."

The rules and regulations deemed wise and efficient, and made at the suggestion of State or municipal boards of health, are swept out of existence, and the Secretary of the Treasury "shall make such rules and regulations as are necessary to prevent the introduction into the United States of any infectious or contagious disease from any foreign port or place, or the spread of such diseases from one domestic port to another," etc., . . . . "to be enforced by consular quarantine and customs offices of the United States, and the State and local quarantine officers of the United States" "with the proviso that they shall not discriminate against any port or place." The laws are to be made by the Secretary of the Treasury and practically carried out under the power of the Supervising Surgeon.General of the National hospital service. Was there ever a law made that was not open to differences of opinion as to its meaning? The State Board of Health of Louisiana were for years trying to enforce their laws as to the collection of dues contracted for quarantine procedures. Is it to be the privilege of the Marine. Hospital Service to take the place of the supreme court of the United States? Who is to adjudicate the proper charges of quarantine procedure, are the same charges to be made in a port of a dozen entries in a year with ports having thousands of vessels enter ing their harbors, like New York, Boston, Philadelphia or New Orleans? All such matters should surely be in the hands of the ports interested.

On page 3 we find that when the Secretary of the Treasury shall deem it necessary, etc., incoming vessels shall be inspected by a National quarantine officer designated or appointed by the Secretary of the Treasury on recommendation of the Surgeon General of the Marine-Hospital Service, and such vessel can not be admitted to entry without the certificates of said officer that the United States quarantine regulations have been complied with.

The quarantine laws for the great cities of the United States are to be made (practically) by the Marine-Hospital Service, and if not satisfactorily carried out in the opinion of that service, an officer is to be sent, recommended by them, to forbid entry as they see proper. Was ever such power granted? Is it the meaning of this bill that every port must yield to this overwhelming power, and pass over their cities to the MarineHospital Service for quarantine government?

On page 6, line 25 says whenever yellow fever, cholera, plague or typhus has passed the quarantines of the United States . . the quarantine regulations of the United States, prepared under the direction of the Secretary of the Treasury, shall be supreme and have precedence of State or municipal laws, rules or regulations, and the President is authorized to enforce the same,"

On page 6, lines 14 and 15 , we find, "and to prevent unneces. sary restrictions upon interstate commerce." Any person violating a prohibition or a permit from the Federal authorities shall be deemed guilty of misdemeanor and shall be subject to a fine of not more than $\$ 1000$ or imprisonment for not more than twelve months, or both, at the discretion of the court.

This is the summum malum. Therefore, any health officer who shall disregard a permit which he regards dangerous to his community, shall wear stripes in a common prison or penitentiary and pay a fine which may beggar him.

There are two quarantines, one in the intereste of health and one in the interests of commerce. The quarantine interests of health and of commerce are ever at variance. It must be so. 